Check for updates

Cite this: Chem. Sci., 2019, 10, 8832

๑ All publication charges for this article have been paid for by the Royal Society of Chemistry

Received 25th May 2019

Accepted 2nd August 2019

DOI: $10.1039 / c 9 s c 02555 c$

rsc.li/chemical-science

\section{Self-curing super-stretchable polymer/microgel complex coacervate gels without covalent bond formation $\uparrow$}

\author{
Shanglin Wu, (D) *a Mingning Zhu, (D) a Dongdong Lu, ${ }^{a}$ Amir H. Milani, (D) a Qing Lian, ${ }^{a}$ \\ Lee A. Fielding, (D) a Brian R. Saunders, (D) *a Matthew J. Derry, (D) ${ }^{\text {b }}$ Steven P. Armes, (D) b \\ Daman Adlam ${ }^{c}$ and Judith A. Hoyland ${ }^{c d}$
}

\begin{abstract}
Elastic physical gels are highly desirable because they can be conveniently prepared and readily shaped. Unfortunately, many elastic physical gels prepared in water require in situ free-radical polymerization during the gel formation stage. In contrast, complex coacervate gels are physical gels that can be prepared by simply mixing two pre-formed oppositely-charged polyelectrolytes. However, as far as we are aware, highly elastic complex coacervate gels have not yet been reported. Herein, we combine polyanionic microgel particles with a well-known commercially-available cationic polyelectrolyte to prepare polymer/microgel complex coacervate (PMCC) physical gels. This new family of gels requires annealing at only $37^{\circ} \mathrm{C}$ and behaves like a covalent gel but does not form covalent bonds. Thermal reconfiguration of the dynamic ionic bonds transforms the shapeable pre-gel into a highly elastic gel that is super-stretchable, adhesive, self-healing, highly swellable and can be further toughened using $\mathrm{Ca}^{2+}$ as an ionic crosslinker. Our PMCC gels have excellent potential for applications as engineering gels and structural biomaterials, as well as for wound healing and water purification.
\end{abstract}

\section{Introduction}

Hydrogels can be prepared with excellent mechanical properties by judicious control of the spatial arrangement and crosslinking mechanism. ${ }^{1-4}$ They have been utilized as tissue scaffolds ${ }^{5-7}$ and injectable implants, ${ }^{8-10}$ as well as for wound healing, ${ }^{11}$ drug delivery, ${ }^{\mathbf{1 2}}$ water purification, ${ }^{\mathbf{1 3}}$ electronic skin, ${ }^{\mathbf{1 4 , 1 5}}$ soft robotics ${ }^{\mathbf{1 6}}$ and energy storage. ${ }^{17}$ Recently, hydrogels have been reported with outstanding tensile fracture stress and strain properties, including double network hydrogels, ${ }^{18}$ nanocomposite hydrogels, ${ }^{19}$ microgel-reinforced hydrogels, ${ }^{20}$ slide-ring hydrogels ${ }^{21}$ and hybrid ionically-crosslinked hydrogels. ${ }^{22}$ One common feature for such gels is that covalent bonds are formed during gel preparation, which limits their potential applications.

${ }^{a}$ School of Materials, University of Manchester, MSS Tower, Manchester, M13 9PL, UK. E-mail: shanglin.wu@postgrad.manchester.ac.uk; brian.saunders@manchester.ac.uk ${ }^{b}$ Department of Chemistry, The University of Sheffield, Dainton Building, Brook Hill, Sheffield, South Yorkshire, S3 $7 H F$, UK

'Division of Cell Matrix Biology and Regenerative Medicine, Faculty of Biology, Medicine and Health, University of Manchester, Oxford Road, Manchester, M13 $9 P T, U K$

${ }^{d}$ NIHR Manchester Biomedical Research Centre, Central Manchester Foundation Trust, Manchester Academic Health Science Centre, Manchester, M13 9WL, UK

$\dagger$ Electronic supplementary information (ESI) available. See DOI: $10.1039 / \mathrm{c} 9 \mathrm{sc} 02555 \mathrm{c}$
In contrast, physical gels do not contain chemical crosslinks and hence can be prepared under mild conditions. ${ }^{2,23-25}$ Some dynamic crosslinked gels can be also formed under physiological conditions based on the Schiff based reaction. ${ }^{26}$ Thus such gels are well-suited for use as biomaterials ${ }^{27}$ and have been constructed using peptides, ${ }^{28}$ hydrogelators, ${ }^{29}$ polyelectrolytes, ${ }^{30}$ crystallization ${ }^{31}$ and polymer-particle association. ${ }^{32}$ Peptide and hydrogelator-based gels utilize reversible association and can repair damage through self-healing. Polymer-particle selfassembled gels have employed reversible attractive hydrophobic interactions between the components. However, these gel networks tend to fail at relatively low strain. ${ }^{32}$

Recently, nanocomposite ${ }^{33}$ and supramolecular ${ }^{34}$ biocompatible hydrogels that are tough and self-healing have been synthesized using free-radical polymerization accompanying host-guest interaction, ${ }^{34}$ hydrogen bonding, ${ }^{33,34}$ electrostatic interaction $^{33}$ and physical entanglement. ${ }^{33}$ Physical hydrogels with such properties have also been prepared from oppositely charged polyelectrolytes. $^{30,35-37}$ These polyelectrolyte complex gels utilize reversible ionic bonds for physical crosslinking and are potentially attractive biomaterials for in vivo applications because covalent crosslinking is not required. However, to avoid the strong association between the pair of oppositely charged polyelectrolytes that would normally form coacervates, ${ }^{38}$ such gel preparation requires in situ polymerization. Because of their high ionic conductivity, polyelectrolyte-based gels may be useful for nerve tissue repair and as cardiac patches. ${ }^{23}$ Complex 
coacervates are widely used in food science ${ }^{39}$ and involve spontaneous phase separation of an aqueous solution of oppositely-charged macromolecules into solvent-rich and solvent-depleted phases. ${ }^{40}$ Similarly, organisms such as the sandcastle worm secrete coacervated proteins that act as adhesives for mineral particles. ${ }^{\mathbf{4 1}}$ The inclusion of solvophilic units within pre-formed triblock copolymers has been exploited to prepare reversible gels formed by charge-driven selfassembly. ${ }^{37,42}$ However, these and other related coacervate gels are not stretchable. ${ }^{43}$ An intriguing question is whether preformed oppositely-charged macromolecules can be designed such that upon mixing produce mechanically robust, stretchable, hydrogels.

Here, we investigate a binary polyelectrolyte combination of an anionic polyacid microgel (termed MG) and a cationic branched polyethyleneimine (PEI). MGs are crosslinked polymer colloids that swell when the $\mathrm{pH}$ approaches the particle $\mathrm{p} K_{\mathrm{a} \cdot}{ }^{44}$ PEI is well known as a vehicle for gene transfer. ${ }^{45}$ In contrast to polyelectrolyte complex gels reported in the literature, ${ }^{37,42,43}$ physical hydrogels with excellent shapeability and stretchability are prepared simply by mixing MG and PEI followed by thermal annealing under mild conditions. A series of polymer/MG complex coacervate (PMCC) gels are prepared by varying the dry weight $\mathrm{PEI} / \mathrm{MG}$ mass ratio. Each gel is denoted by PEI/MG(T-MR), where $T$ is the annealing temperature $\left({ }^{\circ} \mathrm{C}\right)$ and MR corresponds to the PEI-to-MG mass ratio. The heated gels are termed T-gels. For example, PEI/MG(37-0.67) corresponds to a T-gel prepared from a pre-gel using a mass ratio of 0.67 by thermal annealing at $37{ }^{\circ} \mathrm{C}$. We show that these new PMCC gels are shapeable, super-stretchable, self-healing, adhesive, highly swellable and can be toughened using $\mathrm{Ca}^{2+}$.

\section{Results and discussion}

We utilized dynamic ionic bonds introduced by mixing preformed components which could rearrange ${ }^{2}$ to form stronger bonds consisting of multiple ionic bonds between the two components (see Fig. 1A). The pH-responsive PEA-MAA-DVB particles (where EA, MAA and DVB denote ethyl acrylate, methacrylic acid and divinylbenzene, respectively) were previously used to prepare hydrogels of covalently-interlinked $\mathrm{MGs}^{\mathbf{4 6}}$ which differs considerably from the current work. Herein, the MGs had a number-average diameter of $55 \mathrm{~nm}$ as determined from TEM studies (see Fig. S1A, ESI $\dagger$ ) and acid titration gave a $\mathrm{p} K_{\mathrm{a}}$ of 6.5. Branched PEI is a polycationic polymer with a $\mathrm{p} K_{\mathrm{a}}$ of 8.5 for its protonated form. ${ }^{47}$ It has been used for encapsulating cells with microgels ${ }^{48}$ as well as for DNA and RNA transfer into cells. ${ }^{49,50}$ We provide evidence below that the pre-gel "heatsets" to form an elastic T-gel that is highly stretchable. The Tgels swell strongly when the solution $\mathrm{pH}$ exceeds the $\mathrm{p} K_{\mathrm{a}}$ of PEI. However, unlike other polyelectrolyte complexes, ${ }^{42}$ degelation does not occur.

Simply hand-mixing MGs and PEI gave a 'putty like' soft gel that became strongly elastic when annealed at mild temperatures. The pre-gel deformed plastically, could be molded into various shapes and was injectable (see Fig. 1B). Such pre-gels can be formed under physiologically-relevant conditions (e.g.
pH 7.4 and $37{ }^{\circ} \mathrm{C}$ ). The pH-responsive DVB-crosslinked MG building blocks contain a high MAA content (35.8 wt\%). The size and $\mathrm{pH}$-dependent properties of the MGs were characterized using potentiometric titration, dynamic light scattering (DLS) and zeta potential measurements (see Fig. S1, ESI $\dagger$ ). These particles swell substantially from $74 \mathrm{~nm}$ at $\mathrm{pH} 4.7$ to 502 $\mathrm{nm}$ at $\mathrm{pH} 11$ and exhibit highly negative zeta potentials above $\mathrm{pH}$ 6.0. PEI had a manufacturer's molecular weight of $10 \mathrm{kD}$. Remarkably, temperature curing (at 37,50 or $80{ }^{\circ} \mathrm{C}$ for $20 \mathrm{~h}$ ) transformed the deformable pre-gels into highly elastic gels (compare Fig. 1C to Fig. 1B). Hence, the PMCC pre-gels could be shaped and then set in any desired shape simply by heating.

FTIR spectra were recorded for the T-gels cured at 37, 50 or $80{ }^{\circ} \mathrm{C}$ (see Fig. 1D and S2C, ESI $\dagger$ ) and exhibit new bands at 1552 and $1637 \mathrm{~cm}^{-1}$ which are assigned to $-\mathrm{COO}^{-}$(asymmetric stretch) and $-\mathrm{NH}_{3}{ }^{+}$, respectively. ${ }^{51}$ These bands indicate formation of ionic crosslinks. Hydrogen bonding interactions are also indicated by the red shift in the PEI N-H stretch ${ }^{52}$ from 3450 to $3400 \mathrm{~cm}^{-1}$ (see Fig. S2, ESI $\dagger$ ). There was no evidence for the formation of new covalent amide bonds. Hence, the PMCC gels are formed as a result of extensive ionic and hydrogen bonding.

Why do the pre-gels transform to elastic T-gels after heating? We envisage that the MGs act as nanosized crosslinkers and PEI as flexible bridges between adjacent MGs. A related morphology has been reported for covalent nanostructured hydrogels. ${ }^{53}$ Drawing upon atomic force microscopy studies of the interactions between two oppositely charged polyelectrolyte brushes, ${ }^{38}$ we propose that the PEI chains initially adsorbed in a flat conformation and then interpenetrated into the MG peripheries upon annealing (Fig. 1A). Such interpenetration increases the number of ion pairs which is driven, in turn, by the entropy increase due to mobile ion release. ${ }^{54}$ Hence, curing increases the number-density of elastically effective ionic crosslinks which increases gel modulus according to rubber elasticity theory. ${ }^{55}$

Self-healing or self-repairing gels are highly desirable because they offer the possibility of extended operational lifetimes. Fig. 1E shows a stretched PEI/MG(50-0.67) gel formed from two disk halves obtained from two different disks that were cut and then manually interfaced for $24 \mathrm{~h}$ at room temperature. Self-healing occurred, which suggests that dynamic bonds were present. This self-repairing behavior is attributed to the mobile PEI component. ${ }^{48}$ Tensile stress-strain measurements (Fig. S3, ESI $\dagger$ ) showed that the recovery of the initial breaking strain (self-healing efficiency) was 92\%, 64\% and $20 \%$ for the PEI/MG(T-0.67) gels heated at 37,50 and $80{ }^{\circ} \mathrm{C}$, respectively. The less efficient self-healing observed for gels heated at 50 and $80{ }^{\circ} \mathrm{C}$ indicates more extensive ionic bond formation.

Our T-gels adhered to a remarkably wide range of materials (see Fig. 1F). For example, PEI/MG(50-0.67) adhered to plastic, rubber, steel, glass and Teflon. The gel can easily sustain the heavy glassware or steel ( $\sim 150 \mathrm{~g})$ in air. Adhesive strengths of $15.2 \mathrm{kPa}$ and $8.9 \mathrm{kPa}$ were determined for glass and Teflon, respectively (below). The $\mathrm{PEI} / \mathrm{MG}(50-0.67)$ gel also adhered tightly to a model tissue surface (porcine skin) which 

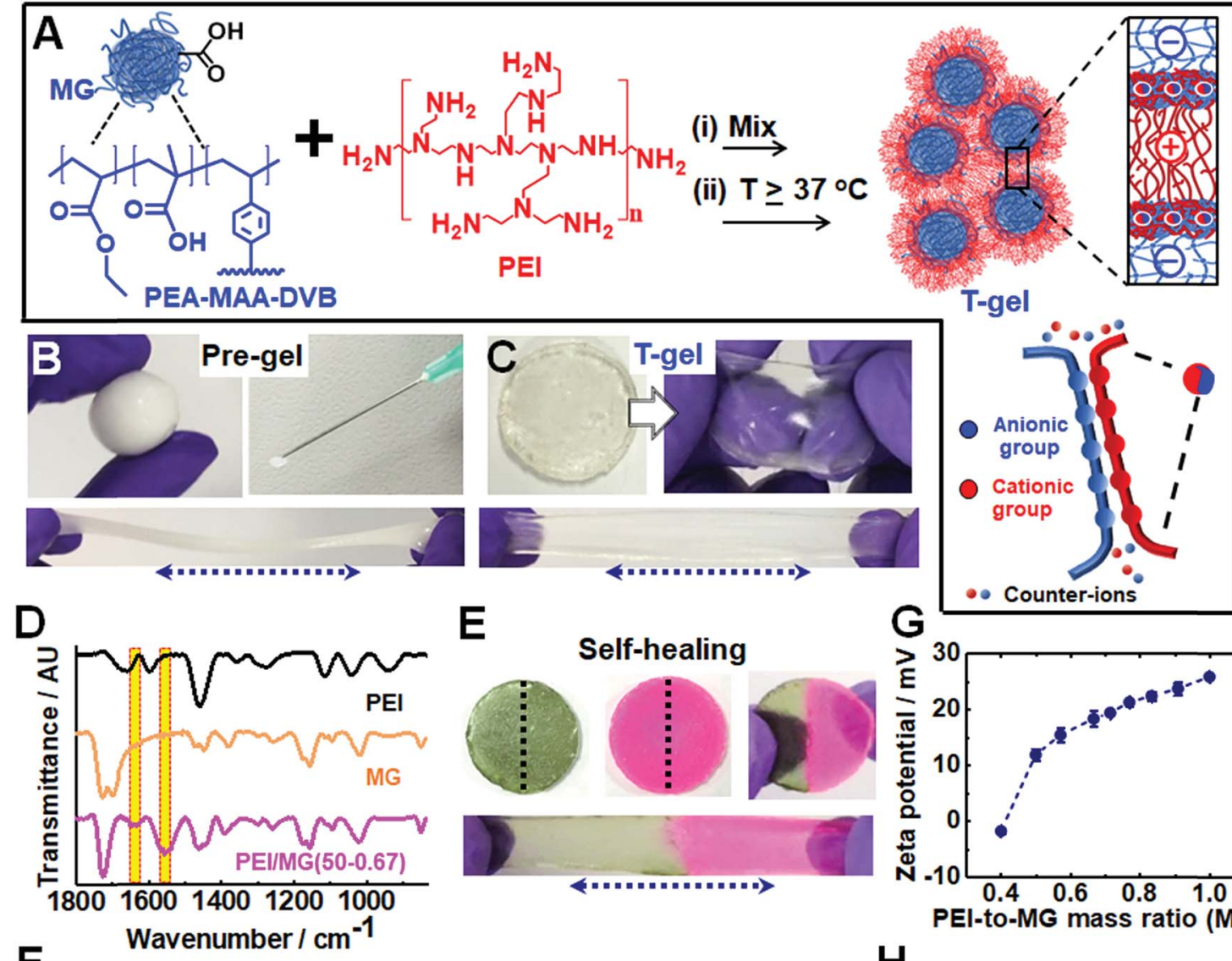

T-gel

F
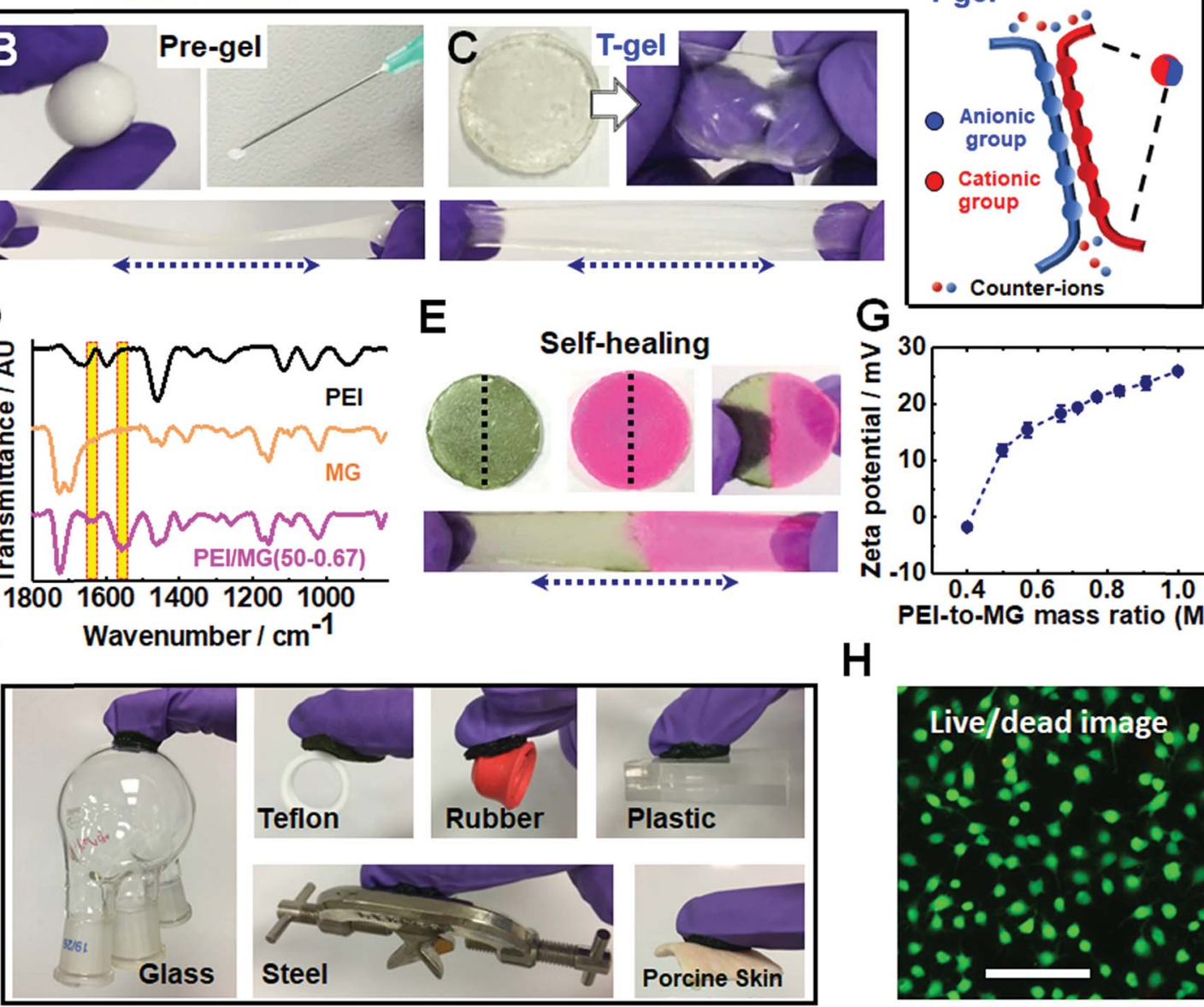

G

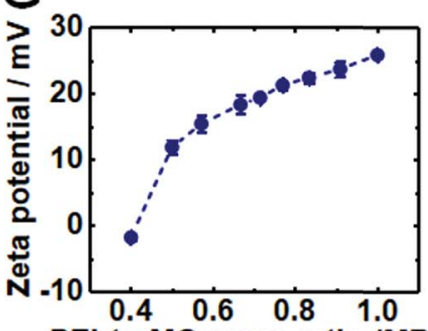

PEI-to-MG mass ratio (MR)

$\mathrm{H}$

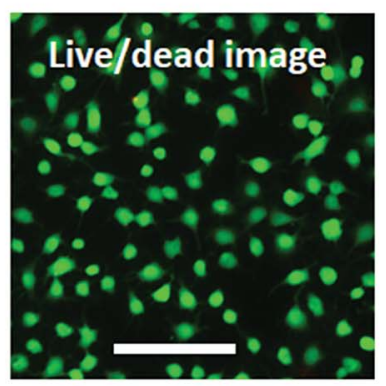

Fig. 1 (A) Schematic representation of PEI/MG hydrogel preparation and cooperative ionic bonding. (B) Plastic flow and injectability of shapeable PEI/MG(0.67) pre-gel. (C) Stretchable behavior of a PEI/MG(50-0.67) T-gel of 19 mm diameter. (D) FTIR spectra for PEI/MG(50-0.67), MG and PEI. (E) Self-healing for the PEI/MG(50-0.67) T-gel (19 mm) after being cut (black dashed line) into two separate parts. Dyes were used to aid clarity. (F) $\mathrm{PEI} / \mathrm{MG}(50-0.67)$ adheres to various materials including glass, Teflon, steel, plastic rubber and porcine skin. (G) Zeta potentials for dilute PEI/MG mixed dispersions recorded for various mass ratios (MR). (H) Live/dead assay for chondrocyte cells in the presence of PEI/MG(50-0.50) after $72 \mathrm{~h}$. Scale bar $100 \mu \mathrm{m}$.

demonstrates its bioadhesive properties and is quantified later. The zeta potential for a dilute PEI/MG dispersion $(\mathrm{MR}=0.67)$ was $+18.3 \mathrm{mV}$ at $\mathrm{pH} 7.3$ (Fig. 1G), which accounts for the strong adhesion to negatively charged surfaces such as glass. The adhesion to Teflon is attributed to the relatively hydrophobic nature of coacervate complexes. ${ }^{38}$ Live/dead assays were measured for chondrocyte cells in the presence of PEI/MG(500.50) gel (Fig. 1H). Additional time points and a control are shown in Fig. S4 (ESI $\dagger$ ). MTT assay results showed that the cell viability after 1,2 and 3 days was $90 \%, 78 \%$ and $70 \%$, respectively (see Fig. S5, ESI $\dagger$ ). The gels had relatively low cytotoxicity.
In principle, the cell viability could be increased by (1) using a PEI/MG gel with a lower MR, (2) chemically functionalising $\mathrm{PEI}^{56}$ and/or (3) chemically crosslinking PEI to prevent any free PEI chains from leaving the gel. ${ }^{48}$

The T-cured gels proved to be highly stretchable (Fig. 2A) (see also Movie S1, ESI $\dagger$ ). The relationship between the tensile stress-strain properties and MR (Fig. 2B) was investigated (see also and Tables S1 and S2 (ESI $\dot{\dagger})$ ). A breaking strain of 1015\% was reached for PEI/MG(50-0.67). The highest Young's modulus $(E=39.0 \mathrm{kPa})$ and strength $(64.0 \mathrm{kPa})$ were obtained for PEI/ MG(50-0.40). As MR increased the MG particles were diluted by 
A

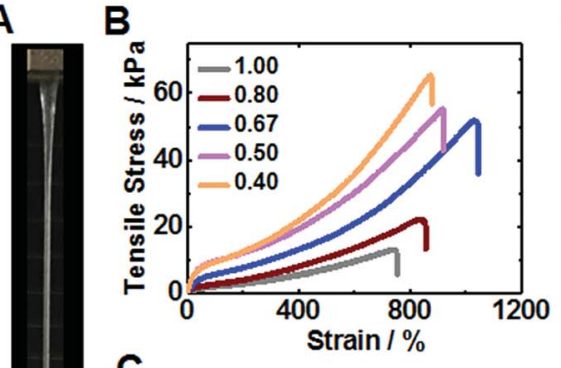

D

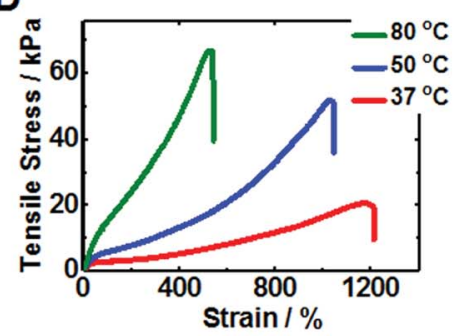

$\mathbf{F}$

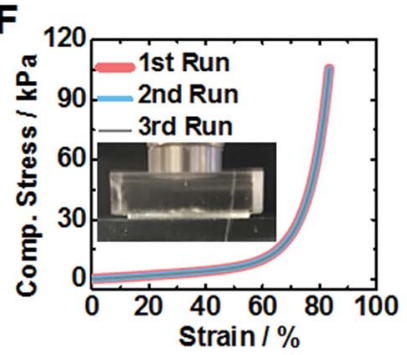

C

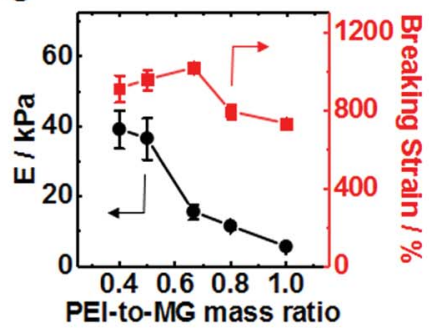

$E$
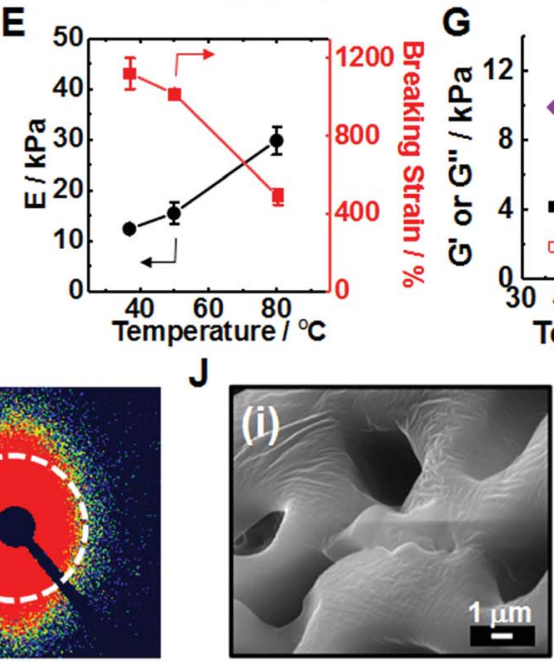
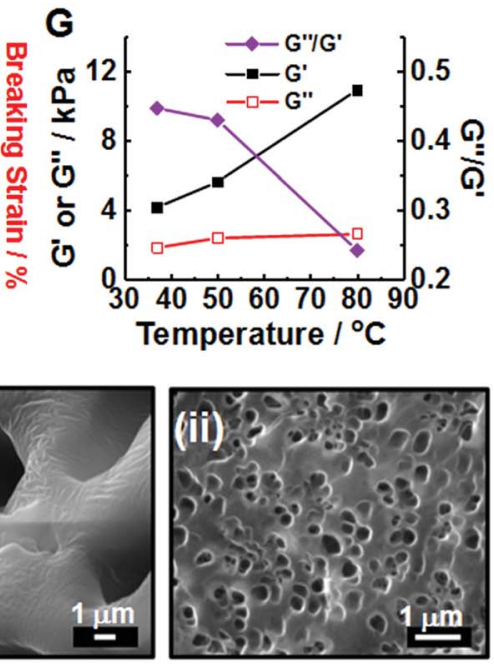

$\mathrm{H}$
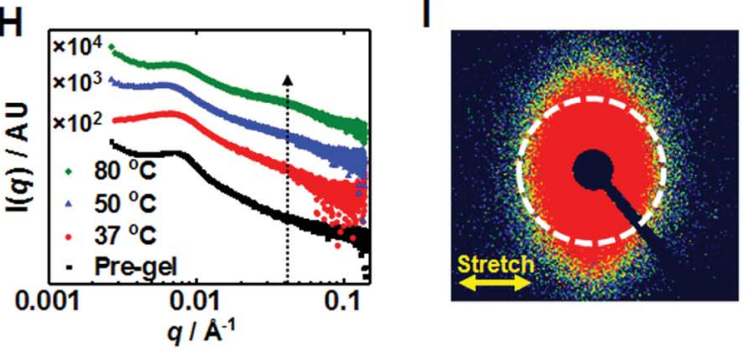

Fig. 2 (A) Stretched PEI/MG(50-0.67) gel prepared at pH 7.3. Uniaxial tensile stress-strain data (B) and modulus and breaking strain (C) for PEI/ $\mathrm{MG}(50-\mathrm{MR})$ gels prepared at $50{ }^{\circ} \mathrm{C}$ using various mass ratios. Tensile stress-strain data (D) and modulus and breaking strain data (E) for PEI/ MG(T-0.67) gels annealed at various temperatures. (F) Multiple uniaxial compressive stress-strain loading cycles for a PEI/MG(50-0.67) gel. (G) Storage modulus $\left(G^{\prime}\right)$, loss modulus $\left(G^{\prime \prime}\right)$ and loss tangent $\left(G^{\prime \prime} / G^{\prime}\right)$ for PEI/MG(T-0.67) gels obtained using a frequency and strain of $1 \mathrm{~Hz}$ and $1 \%$, respectively. (H) 1D SAXS patterns recorded for various PEI/MG(T-0.67) gels. (I) 2D SAXS pattern for a stretched PEI/MG(50-0.67) gel. The strain (direction shown) was 155\%. (J) SEM images of (i) PEI/MG(0.67) pre-gel and (ii) PEI/MG(37-0.67).

PEI and the average separation between MGs increased. Therefore, the PEI bridging length increased and the proportion of crosslinking centers decreased which decreased the modulus (Fig. 2C). The breaking strain passed through a maximum (Fig. 2C) because in the early stages of the MR increase the length of the bridging chains increased. However, at higher MR values fewer PEI chains were able to bridge neighboring MGs. The effect of PEI molecular weight was also investigated. Low molecular weight PEI $(0.60 \mathrm{kD})$ could not form a T-cured elastic gel network (Fig. S6, ESI $\dagger$ ); whereas $70 \mathrm{kD}$ PEI formed a robust gel with $E=14.8 \mathrm{kPa}$. However, the latter gel exhibited a lower breaking strain compared to that of the PEI/MG(50-0.67) gel prepared using $10 \mathrm{kD}$ PEI. The $70 \mathrm{kD}$ PEI gel was not homogenous due to the high viscosity of its pre-gel.

We investigated the effect of annealing temperature on T-gel stretchability. Tensile measurements (Fig. 2D) showed that an PEI/MG(37-0.67) gel (cured at $37{ }^{\circ} \mathrm{C}$ ) exhibited the highest breaking strain of all the gels (1122\%) while an PEI/MG(80-0.67) gel possessed the highest modulus $(29.8 \mathrm{kPa})$ and strength $(62.5$ $\mathrm{kPa})$ with a relatively high breaking strain $(489 \%)$. PEI/MG(500.67 ) had the highest toughness $\left(0.194 \mathrm{MJ} \mathrm{m}^{-3}\right)$ using the area under the stress-strain curve. The annealing time also affected gel mechanical properties. The PEI/MG(80-0.67) gel modulus and breaking strain increased and decreased, respectively, with increasing annealing time (Fig. S7, ESI + ). We propose that thermal annealing accelerates reconfiguration and increases the number-density of ionic bonds (Fig. 1A), leading to higher moduli and lower breaking strain (Fig. 2E). PEI/MG(50-0.67) prepared using $10 \mathrm{kD}$ PEI was judged to have the best overall mechanical properties. This gel also exhibited excellent compressive properties with no failure occurring at $84 \%$ strain even when repeatedly compressed (Fig. 2F). Its Young's modulus of $11.5 \mathrm{kPa}$ compares well with that of muscle. ${ }^{57}$ Cyclic compression data confirmed that the residual strain was proportional to the maximum cycle strain whilst greater hysteresis was observed at higher applied strain (Fig. S8, ESI $\dagger$ ). Frequency-sweep dynamic rheology data were measured for the PEI/MG(T-0.67) gels (see Fig. S9, ESI†े). Fig. 2G shows the variation of the storage modulus $\left(G^{\prime}\right)$, loss modulus $\left(G^{\prime \prime}\right)$ and $G^{\prime \prime} / G^{\prime}$ (=tan $\delta$ ) with cure temperature. The increase with $G^{\prime}$ with temperature follows the same trend as that observed for the Young's modulus in Fig. 2E. The $G^{\prime}$ values increased and $G^{\prime \prime} / G^{\prime}$ decreased with increasing temperature indicating that the gels became increasingly solid-like. ${ }^{58}$

Small-angle X-ray scattering (SAXS) was employed to gain further insight regarding the excellent gel stretchability. 
Immersion of the gels in saturated $\mathrm{CaCl}_{2}$ solution for $30 \mathrm{~s}$ was beneficial because it greatly increases their X-ray scattering contrast. As will be discussed below the MG particles within the PEI/MG gels partially de-swell due to added $\mathrm{Ca}^{2+}$ and the centerto-center distance decreases. However, the MGs were in a highly elastic environment prior to (and after) $\mathrm{Ca}^{2+}$ addition which would have prevented any major changes in the nearest neighbor locations in the gels occurring (e.g., such as aggregation) due to this treatment.

The structure peak observed at $q=0.0065 \AA^{-1}$ for PEI/ MG(50-0.67) (Fig. 2H) corresponds to a mean centre-to-centre distance between neighboring MG particles of $97 \mathrm{~nm}$, which is larger than that observed for a pure $17 \mathrm{wt} \%$ MG dispersion (87 nm, see Fig. S10, ESI $\dagger$ ). The presence of comparable structure peaks in these SAXS patterns supports the view that the SAXS data for the $\mathrm{Ca}^{2+}$-treated gels are representative of the as-made T-gels without $\mathrm{Ca}^{2+}$. A new shoulder emerges at $q$ $=0.04 \AA^{-1}$ after annealing which may indicate greater local order. SAXS studies of a stretched PEI/MG(50-0.67) film (Fig. 2I) revealed a distinctly different anisotropic 2D pattern. This anisotropy was confirmed by azimuthal profile analysis
(Fig. S11, ESI $\dagger$ ) and indicates directional alignment of the submicrometer MGs within the stretched gels. SEM studies showed that the pore size of freeze-dried gels was tuneable using temperature (Fig. 2J). The pre-gel had the largest pores $(5.06 \mu \mathrm{m})$, with the mean pore size being reduced to just 0.34 $\mu \mathrm{m}$ for PEI/MG(37-0.67) (see also Fig. S12, ESI $\dagger$ ).

The dynamic tensile stress-strain data for the PEI/MG(500.67) gel indicated energy dissipation, which increased linearly with maximum strain (see Fig. S13, ESI $\dagger$ ). The maximum stress and dissipated energy rapidly became constant. The lack of change of dissipated energy with cycling implies that chains do not slide past each other. Rather, the sacrificial bonds that were broken are reformed in the absence of stress. The dynamic nature of these ionic (and hydrogen) bonds is a cause of the excellent stretchability of the T-gels.

When the solution $\mathrm{pH}$ is increased beyond the PEI $\mathrm{p} K_{\mathrm{a}}$ of $\sim 8.5$ (ref. 47) the pre-gels expanded to fill the entire fluid volume, but remained a free-standing gel as judged by the tube inversion test, see Fig. 3A. Only in highly alkaline media ( $\mathrm{pH} \sim$ 14) did the pre-gels dissolve (Fig. S14A, ESI $\dagger$ ). The T-gels swelled strongly to form a giant disk (Fig. 3B) at pH 9.8. Intriguingly, the
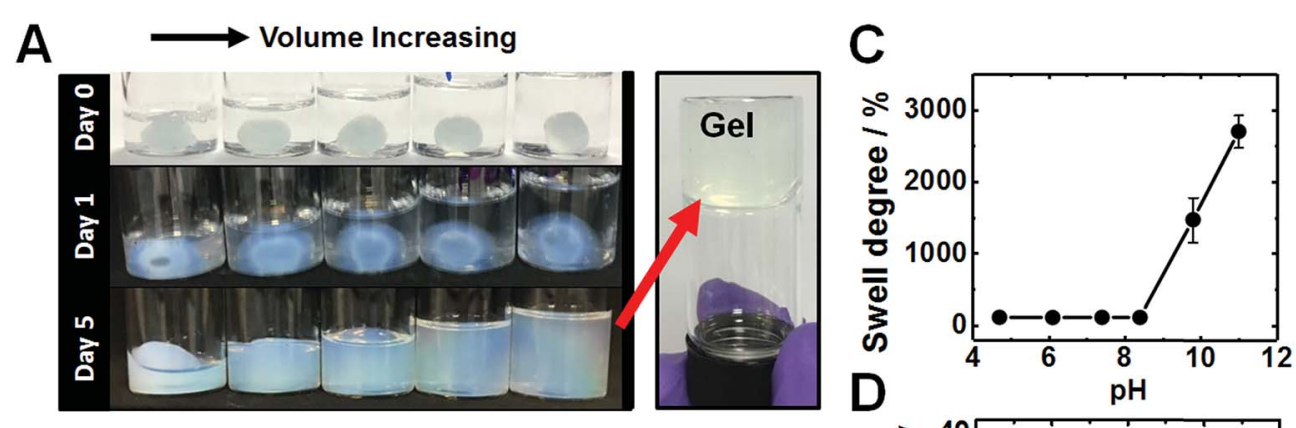

B

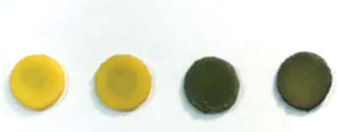

$\mathrm{pH} 4.7$

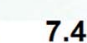

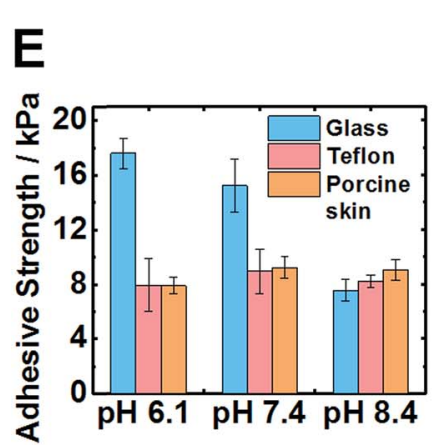

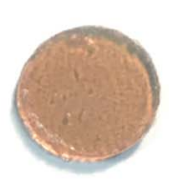

9.8

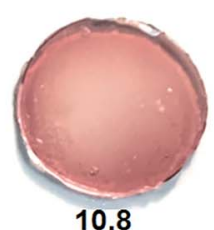

10.8

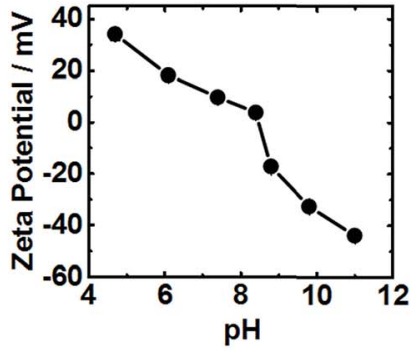

$\mathbf{F}$
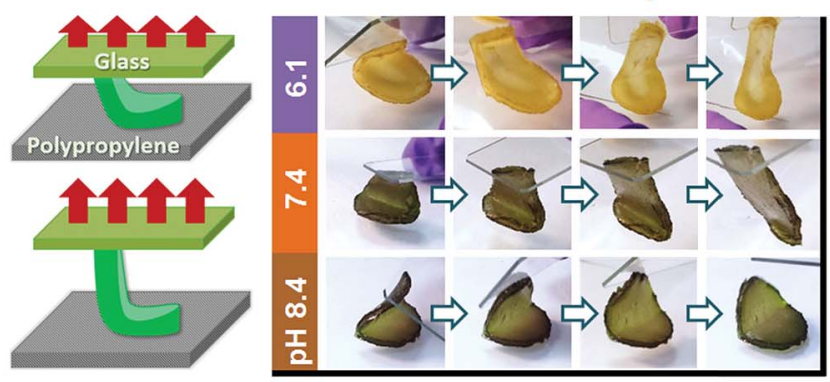

Fig. 3 (A) Aqueous swelling behavior of an PEI/MG(0.67) pre-gel at $\mathrm{pH}$ 11. Such pre-gels swell to fill the available volume. (B) Swelling of an PEI/ $\mathrm{MG}(50-0.67) \mathrm{T}$-gel after immersion in various buffers containing $\mathrm{pH}$-indicator. (C) Degree of swelling for the PEI/MG(50-0.67) gels as a function of solution $\mathrm{pH}$. (D) Zeta potential vs. $\mathrm{pH}$ curves for a dilute aqueous dispersion containing a mixture of PEI/MG(0.67). (E) Adhesion strengths for PEI/MG(50-0.67) gels on glass, Teflon and porcine skin measured at various solution pH values. (F) A "flip test" for PEI/MG(50-0.67) gel to identify the influence of solution $\mathrm{pH}$ on its adhesive strength. The corresponding schematic cartoon shows that glass was in contact with the upper surface of the gel and polypropylene was in contact with its lower surface in such adhesion tests. 
T-gels did not dissolve even at pH 14 (Fig. S14B, ESI $\dagger$ ). This is in striking contrast to the dissolution behavior reported for conventional coacervate gels. ${ }^{42}$ In the $\mathrm{pH}$ range from 4.7 to 8.4, the increase in mass owing to the degree of swelling (w/w\%) was negligible (102-105\%), see Fig. 3C. The swelling degree reached $1470 \%$ at $\mathrm{pH} 9.8$ and $2704 \%$ at $\mathrm{pH} 11$. Zeta potential data for dilute $\mathrm{PEI} / \mathrm{MG}$ dispersions indicated that these hybrid particles (and hence most likely also the pre-gel) became negatively charged above pH 8.4 (Fig. 3D). Additionally, the MG building blocks started to swell above pH 6.1 (see Fig. S1C, ESI $\dagger$ ). At higher $\mathrm{pH}$, ionic crosslinks no longer constrained the gel and the repulsive forces between anionic carboxylate groups caused gel swelling. Nevertheless gel dissolution was prevented.

An interesting question concerning the swollen T-gels is why they do not re-disperse when the $\mathrm{pH}$ exceeds the $\mathrm{p} K_{\mathrm{a}}$ of PEI (Fig. 3B and S14B, ESI $\dagger$ ). We attribute this behavior to persistent PEI bridging between the MGs at high $\mathrm{pH}$. The mechanism for maintaining anchoring of PEI to adjacent MGs is likely to involve multiple hydrogen bonds from interpenetrating PEI and MG chains near the MG peripheries. Candidates for such hydrogen bonds are primary and secondary amine groups from PEI with MG carboxylate and ester groups. ${ }^{59}$

After immersing PEI/MG(50-0.67) gels in various buffers, their adhesion was evaluated using a lap-shear test (see Fig. 3E). The gel contact time was 10 seconds prior to each measurement. Adhesion strengths ranged from 7.5 to $17.5 \mathrm{kPa}$ on both glass, Teflon and porcine skin for all $\mathrm{pH}$ values tested. Interestingly, weaker adhesion was observed for glass at higher $\mathrm{pH}$ (see Fig. 3E). PEI/MG(50-0.67) gel was placed on a smooth polypropylene film. A "flip test" confirmed a reduction in its adhesive strength from $\mathrm{pH} 6.1$ to 8.4 as this gel was released from the upper glass slide (Fig. 3F). The overall surface charge of the gel was positive below $\mathrm{pH}$ 8.4. Hence weaker adhesion to this substrate was observed when the $\mathrm{pH}$ was close to neutral or when the gel acquired negative surface charge. Therefore, electrostatic attraction appears to be the dominant adhesion mechanism below $\mathrm{pH}$ 8.4. In contrast, the adhesive strength of

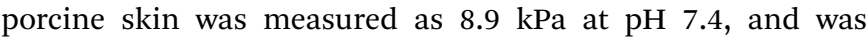
independent of $\mathrm{pH}$ (Fig. 3E). The results are suggestive of a hydrophobic interaction, which has been also reported for a poly( $N$-isopropylacrylamide) based complex coacervates. ${ }^{\mathbf{4 3}}$

Immersion of an PEI/MG(50-0.67) gel into saturated $\mathrm{CaCl}_{2}$ solution caused a time-dependent enhancement of the modulus through ionic crosslinking (depicted in Fig. 4A). The $\mathrm{Ca}^{2+}$-toughened gels were foldable (Fig. 4B) and thin fibers could support relatively heavy loads (Fig. 4C) (see also Table $\mathrm{S} 3 \dagger)$. The gel continuously stiffened for up to $180 \mathrm{~min}$ in $\mathrm{CaCl}_{2}$ $(6.7 \mathrm{M})$ solution (Fig. 4D). An increase in gel modulus was accompanied by a reduction in the breaking strain, but the latter parameter remained above $70 \%$ (Fig. 4E). The modulus increased dramatically from an initial value of $0.016 \mathrm{MPa}$ to 0.30 $\mathrm{MPa}$ and up to $34 \mathrm{MPa}$ after immersion for 0.5 and $180 \mathrm{~min}$, respectively. The latter modulus is a record for coacervate gels. In contrast, saturated $\mathrm{NaCl}$ solution did not discernibly stiffen the gel. Importantly, the T-gels could not be dissolved by soaking in such a solution for more than 3 months when heated at $50{ }^{\circ} \mathrm{C}$ confirming the irreversible formation of these remarkable physical gels. We propose that gel stiffening is the result of $\mathrm{Ca}^{2+}$ crosslinking primarily within the MGs. We characterized the change in structure using SAXS (Fig. 4F). The structure peak moved to a slightly higher $q$ value $\left(0.0070 \AA^{-1}\right)$ which indicates a reduction in center-to-center MG spacing to $90 \mathrm{~nm}$, which is ascribed to partial $\mathrm{MG}$ de-swelling from $\mathrm{Ca}^{2+}$ ionic crosslinking.
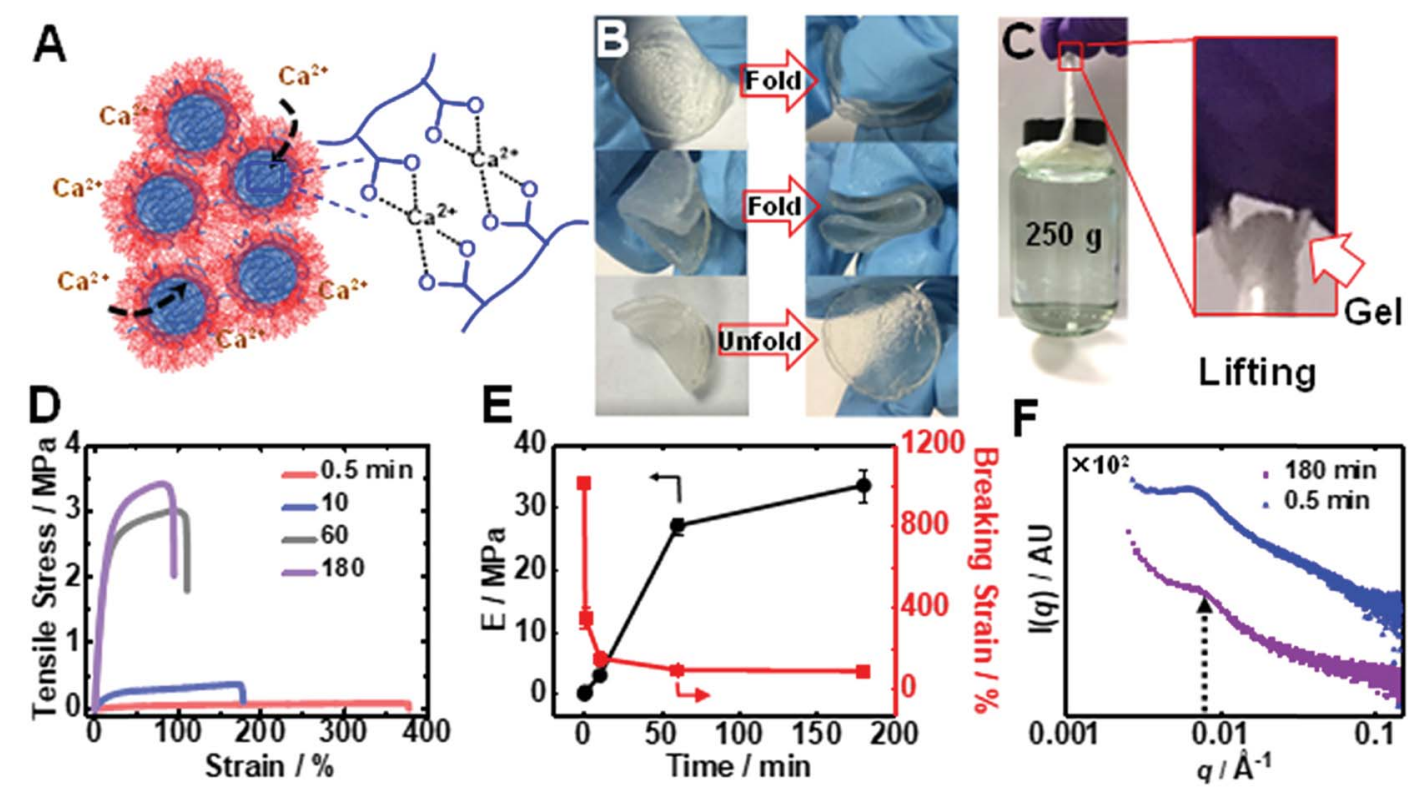

Fig. 4 (A) Depiction of the mechanism for $\mathrm{Ca}^{2+}$-toughening of the PEI/MG T-gels. The $\mathrm{Ca}^{2+}$-toughened gel (180 min soaking time) was foldable (B) and a thin fiber supported a heavy load (C). (D) Tensile data obtained for PEI/MG(50-0.67) exposed to saturated $\mathrm{CaCl}_{2}$ solution for varying times at room temperature. (E) Variation of Young's modulus and strain-at-break with immersion time. (F) 1D SAXS patterns for the gel immersed in saturated $\mathrm{CaCl}_{2}$ solution for 0.5 and $180 \mathrm{~min}$ at room temperature. 


\section{Conclusions}

In summary, by simply mixing oppositely-charged MG and PEI we obtain soft, moldable PMCC gels that can be transformed into strong, elastic physical gels with outstanding mechanical properties under mild conditions $\left(37^{\circ} \mathrm{C}\right.$, neutral $\left.\mathrm{pH}\right)$ without using any covalent crosslinking chemistry. This new family of complex coacervate gels is super-stretchable, self-healable, highly adhesive, super-swellable and dramatically toughened by addition of $\mathrm{Ca}^{2+}$. These new PMCC gels offer potential applications as engineering gels, structural biomaterials including cartilage repair, wound healing, and also for water purification membranes. All gel components are commercially available and there appears to be no barrier to the industrial scale production of PMCC gels.

\section{Conflicts of interest}

The authors declare no conflict of interest.

\section{Acknowledgements}

This work was supported by a 5 years EPSRC Established Career Fellowship awarded to BRS (EP/M002020).

\section{Notes and references}

1 J.-Y. Sun, X. Zhao, W. R. K. Illeperuma, O. Chaudhuri, K. H. Oh, D. J. Mooney, J. J. Vlassak and Z. Suo, Nature, 2012, 489, 133.

2 T. L. Sun, T. Kurokawa, S. Kuroda, A. B. Ihsan, T. Akasaki, K. Sato, M. A. Haque, T. Nakajima and J. P. Gong, Nat. Mater., 2013, 12, 932.

3 P. Rao, T. L. Sun, L. Chen, R. Takahashi, G. Shinohara, H. Guo, D. R. King, T. Kurokawa and J. P. Gong, Adv. Mater., 2018, 30, 1801884.

4 V. X. Truong, M. P. Ablett, S. M. Richardson, J. A. Hoyland and A. P. Dove, J. Am. Chem. Soc., 2015, 137, 1618-1622.

5 J. P. K. Armstrong, J. L. Puetzer, A. Serio, A. G. Guex, M. Kapnisi, A. Breant, Y. Zong, V. Assal, S. C. Skaalure, O. King, T. Murty, C. Meinert, A. C. Franklin, P. G. Bassindale, M. K. Nichols, C. M. Terracciano, D. W. Hutmacher, B. W. Drinkwater, T. J. Klein, A. W. Perriman and M. M. Stevens, Adv. Mater., 2018, 30, 1802649.

6 T. E. Brown, J. S. Silver, B. T. Worrell, I. A. Marozas, F. M. Yavitt, K. A. Günay, C. N. Bowman and K. S. Anseth, J. Am. Chem. Soc., 2018, 140, 11585-11588.

7 H.-p. Lee, L. Gu, D. J. Mooney, M. E. Levenston and O. Chaudhuri, Nat. Mater., 2017, 16, 1243.

8 M. Guvendiren, H. D. Lu and J. A. Burdick, Soft Matter, 2012, 8, 260-272.

9 M. Patenaude and T. Hoare, ACS Macro Lett., 2012, 1, 409413.

10 A. Sinclair, M. B. O'Kelly, T. Bai, H.-C. Hung, P. Jain and S. Jiang, Adv. Mater., 2018, 30, 1803087.
11 D. R. Griffin, W. M. Weaver, P. O. Scumpia, D. Di Carlo and T. Segura, Nat. Mater., 2015, 14, 737.

12 T. R. Hoare and D. S. Kohane, Polymer, 2008, 49, 1993-2007.

13 H. Gao, Y. Sun, J. Zhou, R. Xu and H. Duan, ACS Appl. Mater. Interfaces, 2013, 5, 425-432.

14 M. L. Hammock, A. Chortos, B. C.-K. Tee, J. B.-H. Tok and Z. Bao, Adv. Mater., 2013, 25, 5997-6038.

15 A. Chortos, J. Liu and Z. Bao, Nat. Mater., 2016, 15, 937.

16 S. Bauer, S. Bauer-Gogonea, I. Graz, M. Kaltenbrunner, C. Keplinger and R. Schwödiauer, Adv. Mater., 2014, 26, 149-162.

17 Y. Shi, L. Pan, B. Liu, Y. Wang, Y. Cui, Z. Bao and G. Yu, J. Mater. Chem. A, 2014, 2, 6086-6091.

18 J. P. Gong, Y. Katsuyama, T. Kurokawa and Y. Osada, Adv. Mater., 2003, 15, 1155-1158.

19 K. Haraguchi and T. Takehisa, Adv. Mater., 2002, 14, 11201124.

20 J. Hu, T. Kurokawa, T. Nakajima, T. L. Sun, T. Suekama, Z. L. Wu, S. M. Liang and J. P. Gong, Macromolecules, 2012, 45, 9445-9451.

21 J. Araki and K. Ito, Soft Matter, 2007, 3, 1456-1473.

22 X. Li, H. Wang, D. Li, S. Long, G. Zhang and Z. Wu, ACS Appl. Mater. Interfaces, 2018, 10, 31198-31207.

23 B. Guo and P. X. Ma, Biomacromolecules, 2018, 19, 17641782.

24 W. E. Hennink and C. F. van Nostrum, Adv. Drug Delivery Rev., 2002, 54, 13-36.

25 L. Yu and J. Ding, Chem. Soc. Rev., 2008, 37, 1473-1481.

26 B. Guo, J. Qu, X. Zhao and M. Zhang, Acta Biomater., 2019, 84, 180-193.

27 J. Li, X. Ni and K. W. Leong, J. Biomed. Mater. Res., Part A, 2003, 65A, 196-202.

28 R. J. Mart, R. D. Osborne, M. M. Stevens and R. V. Ulijn, Soft Matter, 2006, 2, 822-835.

29 X. Du, J. Zhou, J. Shi and B. Xu, Chem. Rev., 2015, 115, 1316513307.

30 F. Luo, T. L. Sun, T. Nakajima, T. Kurokawa, Y. Zhao, K. Sato, A. B. Ihsan, X. Li, H. Guo and J. P. Gong, Adv. Mater., 2015, 27, 2722-2727.

31 F. Yokoyama, I. Masada, K. Shimamura, T. Ikawa and K. Monobe, Colloid Polym. Sci., 1986, 264, 595-601.

32 E. A. Appel, M. W. Tibbitt, M. J. Webber, B. A. Mattix, O. Veiseh and R. Langer, Nat. Commun., 2015, 6, 6295.

33 Z. Deng, T. Hu, Q. Lei, J. He, P. X. Ma and B. Guo, ACS Appl. Mater. Interfaces, 2019, 11, 6796-6808.

34 Z. Deng, Y. Guo, X. Zhao, P. X. Ma and B. Guo, Chem. Mater., 2018, 30, 1729-1742.

35 W. Li, R. Feng, R. Wang, D. Li, W. Jiang, H. Liu, Z. Guo, M. J. Serpe and L. Hu, J. Mater. Chem. B, 2018, 6, 4799-4807. 36 S. Ladet, L. David and A. Domard, Nature, 2008, 452, 76.

37 D. V. Krogstad, N. A. Lynd, S.-H. Choi, J. M. Spruell, C. J. Hawker, E. J. Kramer and M. V. Tirrell, Macromolecules, 2013, 46, 1512-1518.

38 J. van der Gucht, E. Spruijt, M. Lemmers and M. A. Cohen Stuart, J. Colloid Interface Sci., 2011, 361, 407-422.

39 C. Schmitt and S. L. Turgeon, Adv. Colloid Interface Sci., 2011, 167, 63-70. 
40 H. Shao and R. J. Stewart, Adv. Mater., 2010, 22, 729-733.

41 H. Zhao, C. Sun, R. J. Stewart and J. H. Waite, J. Biol. Chem., 2005, 280, 42938-42944.

42 M. Lemmers, J. Sprakel, I. K. Voets, J. van der Gucht and M. A. Cohen Stuart, Angew. Chem., Int. Ed., 2010, 49, 708-711.

43 M. Dompé, F. J. Cedano-Serrano, O. Heckert, N. van den Heuvel, J. van der Gucht, Y. Tran, D. Hourdet, C. Creton and M. Kamperman, Adv. Mater., 2019, 1808179.

44 B. R. Saunders and B. Vincent, Adv. Colloid Interface Sci., 1999, 80, 1-25.

45 C. L. Gebhart and A. V. Kabanov, J. Controlled Release, 2001, 73, 401-416.

46 Z. Cui, W. Wang, M. Obeng, M. Chen, S. Wu, I. Kinloch and B. R. Saunders, Soft Matter, 2016, 12, 6985-6994.

47 S. Choosakoonkriang, B. A. Lobo, G. S. Koe, J. G. Koe and C. R. Middaugh, J. Pharm. Sci., 2003, 92, 1710-1722.

48 S. Saxena and L. A. Lyon, Mol. Syst. Des. Eng., 2016, 1, 189201.

49 O. Boussif, F. Lezoualc'h, M. A. Zanta, M. D. Mergny, D. Scherman, B. Demeneix and J. P. Behr, Proc. Natl. Acad. Sci. U. S. A., 1995, 92, 7297-7301.
50 M. E. Johnson, J. Shon, B. M. Guan, J. P. Patterson, N. J. Oldenhuis, A. C. Eldredge, N. C. Gianneschi and Z. Guan, Bioconjugate Chem., 2016, 27, 1784-1788.

51 C. Peniche, W. Argüelles-Monal, N. Davidenko, R. Sastre, A. Gallardo and J. San Román, Biomaterials, 1999, 20, 1869-1878.

52 H. Yuk, T. Zhang, S. Lin, G. A. Parada and X. Zhao, Nat. Mater., 2015, 15, 190.

53 L.-W. Xia, R. Xie, X.-J. Ju, W. Wang, Q. Chen and L.-Y. Chu, Nat. Commun., 2013, 4, 2226.

54 V. S. Rathee, H. Sidky, B. J. Sikora and J. K. Whitmer, J. Am. Chem. Soc., 2018, 140, 15319-15328.

55 L. R. G. Treloar, The physics of rubber elasticity, Oxford Univ. Press, 1975.

56 A. Zintchenko, A. Philipp, A. Dehshahri and E. Wagner, Bioconjugate Chem., 2008, 19, 1448-1455.

57 A. J. Engler, M. A. Griffin, S. Sen, C. G. Bönnemann, H. L. Sweeney and D. E. Discher, J. Cell Biol., 2004, 166, 877-887.

58 E. Kristo, C. G. Biliaderis and N. Tzanetakis, Food Chem., 2003, 83, 437-446.

59 C. L. Perrin and J. B. Nielson, Annu. Rev. Phys. Chem., 1997, 48, 511-544. 